\title{
Quantification of Soluble Egg Antigen and Immunoglobulin E Levels in Serum of Schistosoma haematobium Infected Individuals in Relation to Egg Count in Urine
}

\author{
Elfadil Abdelbagi ${ }^{1}$, Musa $\mathrm{HA}^{2}$, Hammad AG ${ }^{3}$, Osman MA ${ }^{4}$, Bashir A $^{5}$, Alfarazdeg A $^{6}$ and Nawal Eltayeb Omer ${ }^{*}$ \\ ${ }^{1}$ Department of Immunology, National Ribat University, Sudan \\ ${ }^{2}$ Department of Microbiology, National Ribat University, Sudan \\ ${ }^{3}$ Department of Parasitology, National Ribat University, Sudan \\ ${ }^{4}$ Department of Microbiology, University of Bacht Elruda, Sudan \\ ${ }^{5}$ Department of Microbiology, National Ribat University, Sudan \\ ${ }^{6}$ Department of Biochemistry, Khartoum University, Sudan \\ ${ }^{7}$ Department of Pathology, Khartoum College of Medical Sciences, Sudan
}

"Corresponding author: Nawal Eltayeb Omer, Department of Pathology, Khartoum College of Medical Sciences, Khartoum 10995 , Sudan, Tel: +249 571 822 022; Email: gelas3@hotmail.com

Received date: April 12, 2015; Accepted date: August 03 2015; Published date: August 07, 2015

Copyright: $\odot 2015$ Abdelbagi E. This is an open-access article distributed under the terms of the Creative Commons Attribution License, which permits unrestricted use, distribution, and reproduction in any medium, provided the original author and source are credited.

\begin{abstract}
Egg count in urine (parasitology) is the widely accepted approach for quantifying $S$. haematobium infection levels in a population; however the parasitological method is less sensitive in light infections. In the present study we used an assay that detects soluble egg antigen in sera and related that to egg count and the production of IgE. Eighty five sera from egg positive individuals and 5 samples of healthy individuals in Eldwam locality -an endemic area of $S$. haematobium and 3 healthy individuals from non-endemic area were tested. Concentrations of soluble egg antigen (SEA) in serum are as sensitive as egg count in urine and can be more sensitive in detecting infections in individuals with light infection and negative urine for the eggs.
\end{abstract}

Keywords: Schistosoma haematobium; Soluble egg antigen (SEA); IgE; ELISA

\section{Introduction}

Schistosomiasis, also known as bilharziasis or bilharzia [1], is an ancient disease [2], caused by digenetic trematodes of the genus Schistosoma. Seven Schistosome species are known to cause the disease: $S$. haematobium, $S$. mansoni, $S$. japonicum, $S$. intercalatum, $S$. malayensis, $S$. mekongi and $S$. sinensium [3]. Burden of disease is attributed to the three major human schistosome species (Schistosoma mansoni, $S$. haematobium, and $S$. japonicum) [4-6]. The life cycle requires surface freshwater in which the parasite eggs from infected humans will hatch into miracidia. The miracidia penetrate an appropriate aquatic snail where they mature into cercariae. The cercariae then leaves the snail and penetrates the human skin and develops inside the body to maturity, The matured schistosomes have separate sexes and the male body has a groove where the female is held for the rest of its life, releasing fertilized eggs. Sequels of chronic Schistosomiasis include growth stunting, poor school performance, poor work productivity, and continued poverty. It remains one of the most prevalent parasitic infections and has significant economic and public health consequences. Of the world's 207 million estimated cases of schistosomiasis, 93\% (192 million) occur in Sub-Saharan Africa [7]. Worldwide 732 million persons are estimated to be at risk (WHO schistosomiasis fact sheet, 2014). In Sudan surveys conducted in the year 2004 for both urinary and intestinal schistosomiasis in Gezira and White Nile states showed a prevalence rate of $14.3 \%$ and $22.4 \%$ in Gezira and $40 \%$ and $56.7 \%$ in the White Nile. $53.3 \%$ for urinary schistosomiasis in the Blue Nile, $49.3 \%$ for intestinal schistosomiasis in Gadariff and 35.9\% in new HaIfa (NSCP (2005 and 2008).

The detection of schistosome eggs in feces or urine is diagnostic of Schistosomiasis [8]. The use of formalin-based techniques for sedimentation and concentration may increase the diagnostic yield. The miracidium-hatching test is also a useful test. Kato-Katz thicksmear stool examination is widely used in field studies and national control programs to determine the burden of eggs in feces. Mean egg burdens have been correlated with the mean severity of disease. This mean egg burden has in turn correlated to the level of urinary soluble egg antigen. New methods aimed at improving the diagnosis of schistosomiasis have been evaluated [3]. Sensitive and specific diagnostic tests based on antibody-detection are available, and since they meet ASSURED criteria (affordable, sensitive, specific, userfriendly, rapid, equipment-free, deliverable) are the most likely to be useful in schistosome-endemic areas of low-middle income countries [5], a recent report proved the value of a rapid test based on the same methods.

\section{Aim of the Study}

Since World Health Organization (WHO) recommends that infection levels are determined prior to designing and implementing control programmes, as the treatment regimens depend on the population infection prevalence and the sensitivity of the parasitological infection diagnostic method is less reliable when infection levels are low. In this study we aimed to compare between 
Citation: Abdelbagi E, Musa HA, Hammad AG, Osman MA, Bashir A, et al. (2015) Quantification of Soluble Egg Antigen and Immunoglobulin E Levels in Serum of Schistosoma haematobium Infected Individuals in Relation to Egg Count in Urine. J Bacteriol Parasitol 6: 233. doi: $10.4172 / 2155-9597.1000233$

Page 2 of 4

parasitological methods and serological ones in diagnosing infected individuals in an endemic area.

\section{Ethical Consideration}

Ethical and institutional approval for the study was obtained from the medical research council of the National Ribat University. Permission for initiation of the study in the area was obtained from the Health Services Director (Eldwam locality). Objectives and methods were clearly explained to the community. Oral consent was obtained from the participants and parents/guardian before sampling.

\section{Materials and Methods}

\section{Study area}

This study was conducted in Eldweam locality which is approximately $120 \mathrm{Km}$ south to Khartoum. It is a well-known Schistosoma haematobium endemic zone in White Nile state in Sudan. The principle source of water is White Nile river and there are large farms which grow sugar cane for sugar industry, also grow maize, wheat and vegetables. Fishing is carried in the White Nile. Temporary pools are created by the over flow of the White Nile during the rainy season. This locality was chosen because there is no other helminthic infections and low Schistsoma mansoni prevalence [9-11].

\section{Study population}

A total of 85 Sudanese patients from Eldweam locality whom were tested positive for Schistosoma haematobium eggs in urine were recruited in this study. 5 persons from the same locality whom were tested negative for Schistosoma haematobium eggs in urine and 3 healthy controls from a non-endemic area. Samples were collected during January 2014.

\section{Sampling and Procedures}

\section{Urine collection and examination}

A single terminal urine sample $(20-50 \mathrm{ml})$ was collected in $50 \mathrm{ml}$ capacity container from each individual of the study target population. The samples were obtained between 10:00 AM and 14:00 PM. Few drops of saponin solution were added to the samples with visible hematuria to enhance clarity in microscopy [9]. The specimens were appropriately labeled with identification numbers and processed within one hour of collection. At field, $10 \mathrm{ml}$ was filtered through a 25 $\mathrm{mm}$ nucleopore filter $(12 \mu \mathrm{m}$ pore size) [8]. The filter was then placed on glass slide and examined microscopically for the presence of Schistosoma haematobium eggs. The intensity was reported as number of egg/10 ml urine. The degree of intensity was categorized as light infection ( $\leq 50 \mathrm{ova} / 10 \mathrm{ml}$ of urine) and as heavy infection ( $>50 \mathrm{ova} / 10$ $\mathrm{ml}$ urine) [12]. The same is applied for five individuals from the same area with no past history of Schistosoma infection, and additional 3 healthy individuals from anon endemic area.

All the participants who tested positive for Schistosoma haematobium eggs in urine offered anti-helminthic treatment with the recommended dose of praziquantel, $40 \mathrm{mg} / \mathrm{Kg}$ body weight.

\section{Blood samples}

Five milliliter of venous blood was collected from volunteers who tested positive for Schistosoma haematobium eggs in urine. The sera were separated using centrifugation at $3000 \mathrm{rpm}$ for 10 minutes, and the sera aliquoted in cryo-tubes and stored frozen at $-20^{\circ} \mathrm{C}$. All the samples were transported frozen in cold box to the laboratory of Parasitology Department in the College of Medical laboratory Sciences, the National Ribat University, and stored at $-80^{\circ} \mathrm{C}$ until used later. For detection of Schistosoma Soluble Egg Antigen (S EA), Human Schistosoma ELISA kit, with cat no. CSB-E05034th were purchased from Europe-sunny. Before starting the reagent and the samples were putting in room temperature $\left(18-25^{\circ} \mathrm{C}\right)$ for $30 \mathrm{~min}$. Serum samples were diluted 50 -fold in sample diluents $(5 \mu \mathrm{l}$ serum to $245 \mu$ of sample diluents). The micro plate was laid out, well A1 for blank and B1 for negative control and $\mathrm{C} 1$ for positive control. The rest of the wells were used for samples, blank well was set without any solution, $100 \mu \mathrm{l}$ of control serum (negative and positive) and diluted samples were pipetted with new disposable tip into appropriate well. The micro plate was covered with adhesive strip and incubated for 10 minutes at 37. The wells were washed three time with $300 \mu \mathrm{l}$ of washing solution $1 \mathrm{x}$ concentration, after the last wash it was tapped against absorbance paper, $100 \mu \mathrm{l}$ of conjugate were added into each well, except blank [13-15]. The plate were covered and incubated for 10 minutes at $37^{\circ} \mathrm{C}$. Then washed with $300 \mu$ of washing solution per well and then tapped against absorbance paper, $50 \mu \mathrm{l}$ of substrate A and $50 \mu$ of substrate B solution was pipetted to each well. The plate was incubated for 5 minute at $37^{\circ} \mathrm{C}$, protected from light, $50 \mu$ of stop solution were added into each well. The plate tapped gently to ensure thoroughly mixing, then reading was made on micro plate reader at $450 \mathrm{~nm}$ within 10 minutes after addition of stopping reagent [16-20].

For measuring immunoglobulin E (IgE), the "DS.EIA.IgE.Total" is used which is a one-step immunoassay, based on principle sandwich method. The assay utilizes two high affinity and specificity monoclonal antibodies (enzyme conjugated and immobilized), that can bind to two different epitomes on the intact IgE molecule. Following kit protocol a total of 93 sera were tested 85 case sera, 5 sera of health controls from endemic area. 3 sera of health controls from non-endemic area.

\section{Statistical analysis}

The data were analyzed using Statistical Package for Social Sciences (SPSS version, 17). The Pearson and spearman's correlation were computed to examine the association between soluble egg antigen concentration and egg count.

\section{Results}

Egg count in urine ranged between $0-430 \mathrm{egg} / 10 \mathrm{ml}$ of urine, mean intensity of the egg count was 61.92 eggs $/ 10 \mathrm{ml}$ urine. The highest rate of infection was found among young people aged 10-19 year (Table 1). There was a significant difference, in the prevalence of infection, between males and females, $51(60 \%)$ and $34(40 \%)$ respectively. 53.1 $\%$ were light infections and $46.9 \%$ were heavy infections.

\begin{tabular}{|l|l|l|}
\hline Age/Years & Frequency & $\%$ \\
\hline$<10$ & 20 & 23.53 \\
\hline $10-19$ & 63 & 74.12 \\
\hline$\geq 20$ & 2 & 2.35 \\
\hline
\end{tabular}


Citation: Abdelbagi E, Musa HA, Hammad AG, Osman MA, Bashir A, et al. (2015) Quantification of Soluble Egg Antigen and Immunoglobulin E Levels in Serum of Schistosoma haematobium Infected Individuals in Relation to Egg Count in Urine. J Bacteriol Parasitol 6: 233. doi: $10.4172 / 2155-9597.1000233$

Page 3 of 4

Total 85 100

Table 1: Age (years) distribution among the patients.

Mean optic density of soluble egg antigen (SEA) was 0.65 and it was positive in all patients positive for egg in urine (ranges from 0.177-1.510) and also positive in controls from endemic area with no eggs in urine (ranges $0.155-0.336$ ), but negative in controls from nonendemic area with no egg in urine (range from 0.098-0.181). Table 2 shows Correlation between optic density of soluble egg antigen (SEA) in the serum and number of egg/ $10 \mathrm{ml}$ of urine in the patients group.

\begin{tabular}{|c|c|c|c|c|c|c|}
\hline \multirow{3}{*}{$\begin{array}{l}\text { Optic density of } \\
\text { soluble } \\
\text { antigen(SEA) in } \\
\text { the serum }\end{array}$} & \multicolumn{4}{|c|}{ Number of egg/10 $\mathrm{ml}$ of urine } & \multicolumn{2}{|l|}{ Total } \\
\hline & \multicolumn{2}{|l|}{$\leq 50$} & \multicolumn{2}{|l|}{$>50$} & \multirow[b]{2}{*}{ Freq. } & \multirow[b]{2}{*}{$\%$} \\
\hline & Freq. & $\%$ & Freq. & $\%$ & & \\
\hline$<0.50$ & 18 & 21.18 & 9 & 10.59 & 27 & 31.76 \\
\hline
\end{tabular}

\begin{tabular}{|l|l|l|l|l|l|l|}
\hline $0.50-0.99$ & 28 & 32.94 & 20 & 23.53 & 48 & 56.48 \\
\hline$\geq 1.0$ & 4 & 4.70 & 6 & 7.06 & 10 & 11.76 \\
\hline Total & 50 & 58.82 & 35 & 41.18 & 85 & 100 \\
\hline
\end{tabular}

Table 2: Correlation between optic density of soluble egg antigen (SEA) in the serum and number of egg $/ 10 \mathrm{ml}$ of urine in the patients group.

The mean concentration of immunoglobulin E (IgE) among the patients is $519.75 \mathrm{IU} / \mathrm{ml}$. Among controls from endemic areas the mean of concentration is $523.78 \mathrm{IU} / \mathrm{ml}$ and it was negative among controls from non-endemic area. Female patients were found to produce higher concentrations of anti-SEA IgE, than males. Table 3 shows correlation between concentrations of immunoglobulin E ( IgE) $(\mathrm{IU} / \mathrm{ml})$ in the serum and number of egg $/ 10 \mathrm{ml}$ of urine in the patients group.

\begin{tabular}{|c|c|c|c|c|c|c|}
\hline \multirow{3}{*}{$\begin{array}{l}\text { concentrations of } \\
E(\lg E)(I U / m l)\end{array}$} & \multicolumn{4}{|c|}{ Number of egg/10 $\mathrm{ml}$ of urine } & \multicolumn{2}{|l|}{ Total } \\
\hline & \multicolumn{2}{|l|}{$\leq \mathbf{5 0}$} & \multicolumn{2}{|l|}{$>50$} & \multirow[b]{2}{*}{ Freq. } & \multirow[b]{2}{*}{$\%$} \\
\hline & Freq. & $\%$ & Freq. & $\%$ & & \\
\hline$<500$ & 21 & 24.70 & 16 & 18.82 & 37 & 43.53 \\
\hline $500-999$ & 23 & 27.06 & 16 & 18.82 & 39 & 45.88 \\
\hline$\geq 1000$ & 6 & 7.06 & 3 & 3.54 & 9 & 10.59 \\
\hline Total & 50 & 58.82 & 35 & 41.18 & 85 & 100 \\
\hline
\end{tabular}

Table 3: Correlation between concentrations of immunoglobulin E (IgE)(IU/ml) in the serum and number of egg/10ml of urine in the patients group.

There were no statistical significant correlation between three variable (intensity of the eggs in urine, serum concentration of IgE and SEA).

\section{Discussion}

In this study the highest frequency (74.12\%) of infection was found among young individuals (Table 1) in consisting with a previous report from the same state [6]. There is more light infection than heavy infection in the study sample which fits a negative binomial curve [7]. In our study all the patients tested positive for the eggs in urine were found to be positive for the SEA in the serum, even controls from the endemic area with negative urine for the eggs were positive for the serum SEA, but controls from non-endemic area were negative. Unlike adult worm antigens that provide information on the worm burden, egg antigens provide information on the egg burden and it is a good parameter for the assessment of pathology and it could be demonstrated in significant amounts even when egg count is very low or not detected [21-24]. High levels of SEA were detected among heavy egg count in urine (Table 2), this reflects findings of which stated that higher concentrations of SEA in urine are associated with higher egg burden since when concentrations are high in serum they will be high in urine too. In this study there was high production of IgE among infected and uninfected resident in the study area (endemic) compared with the non-endemic resident. This indicates evidence of exposure to the infection [25-28]. Of particular interest is the IgE elicited by the majority of the volunteers at all ages. This is comparable with that obtained by [20]. We deduce that immune mechanisms arising from these antibodies are active at a very young age and these antibodies appear protective as reported by Mduluza et al. [29].The relatively high levels of IgE in the control group from the endemic area may indicate resistance to re- infection with Schistosoma haematobium [14].

\section{Conclusion}

In conclusion the detection of soluble egg antigen in serum could be useful tool in mounting the prevalence of Schistosoma haematobium in endemic areas as well as a diagnostic tool to assess query false negative results.

\section{References}

1. Lengeler C, Utzinger J, Tanner M (2002) Screening for schistosomiasis with questionnaires. Trends Parasitol 18: 375-377. 1

2. Archibald RG (1933) The endemiology and epidemiology of schistosomiasis in the Sudan. J of Trop Med and Hyg 36: 345-348. 2

3. Stothard JR, Sousa-Figueiredo JC, Betson M, Bustinduy A, ReinhardRupp J (2013) Schistosomiasis in African infants and preschool children: let them now be treated! Trends Parasitol 29: 197-205. 3

4. Chitsulo L, Engels D, Montresor A, Savioli L (2000) The global status of schistosomiasis and its control. Acta Trop 77: 41-51. 
Citation: Abdelbagi E, Musa HA, Hammad AG, Osman MA, Bashir A, et al. (2015) Quantification of Soluble Egg Antigen and Immunoglobulin E Levels in Serum of Schistosoma haematobium Infected Individuals in Relation to Egg Count in Urine. J Bacteriol Parasitol 6: 233. doi: $10.4172 / 2155-9597.1000233$

Page 4 of 4

5. [No authors listed] (1993) Public health impact of schistosomiasis: disease and mortality. WHO Expert Committee on the Control of Schistosomiasis. Bull World Health Organ 71: 657-662. 4

6. Tan H, Yang M, Wu Z, Zhou J, Liu A, et al. (2004) Rapid screening method for Schistosoma japonicum infection using questionnaires in flood area of the People's Republic of China. Acta Trop 90: 1-9. 5

7. Lengeler C, Utzinger J, Tanner M (2002) Questionnaires for rapid screening of schistosomiasis in sub-Saharan Africa. Bull World Health Organ 80: 235-242.

8. Peters PA, Warren KS, Mahmoud AA (1976) Rapid, accurate quantification of schistosome eggs via nuclepore filters. J Parasitol 62: 154-155.

9. Cheesbrough M (1998) District laboratory Practice in Tropical Countries. Part 1. Cambridge University Press, London.

10. Ahmed ES, Daffalla A, Christensen NO, Madsen H (1996) Patterns of infection and transmission of human schistosomiasis mansoni and schistosomiasis haematobium in White Nile Province, Sudan. Ann Trop Med Parasitol 90: 173-180. 6

11. Mahmoud AAF (2000) Trematodes (schistosomiasis) and other flukes In: Mendel GL, Bennett JE, Dolin R (eds.) Mendel, Douglas and Bennett's Principles and practice of infection Diseases. Churchill Livingston, New York, pp. 2950-2956.

12. Tanner M, Holzer B, Marti HP, Saladin B, Degrémont AA (1983) Frequency of haematuria and proteinuria among Schistosoma haematobium infected children of two communities from Liberia and Tanzania. Acta Trop 40: 231-237.

13. Kahama AI, Nibbeling HA, van Zeyl RJ, Vennervald BJ, Ouma JH, et al. (1998) Detection and quantification of soluble egg antigen in urine of Schistosoma haematobium-infected children from Kenya. Am J Trop Med Hyg 59: 769-774.

14. Van Lieshout L, De Jonge N, El Masry NA, Mansour MM, Krijer FW, et al. (1992) Improved diagnostic performance of the circulating antigen assay in human Schistosomiasis by parallel testing for circulating anodic and cathodic antigens in serum and urine. AM J Trop Med Hyg 47: 463-469.

15. Braun-Munzinger RA, Southgate BA (1992) Repeatability and reproducibility of egg counts of Schistosoma haematobium in urine. Trop Med Parasitol 43: 149-154.

16. Doehring E, Vester U, Ehrich JH, Feldmeier H (1985) Circadian variation of ova excretion, proteinuria, hematuria, and leukocyturia in urinary schistosomiasis. Kidney Int 27: 667-671.

17. Deelder AM, Qian ZL, Kremsner PG, Acosta L, Rabello AL, et al. (1994) Quantitative diagnosis of Schistosoma infections by measurement of circulating antigens in serum and urine. Trop Geogr Med 46: 233-238.
18. Murare HM, Taylor P (1987) Haematuria and proteinuria during Schistosoma haematobium infection: relationship to intensity of infection and the value of chemical reagent strips for pre- and posttreatment diagnosis. Trans R Soc Trop Med Hyg 81: 426-430.

19. Mott KE, Dixon H, Osei-Tutu E, England EC, Ekue K, et al. (1985) Evaluation of reagent strips in urine tests for detection of Schistosoma haematobium infection: a comparative study in Ghana and Zambia. Bull World Health Organ 63: 125-133.

20. Feldmeier H, Doehring E, Daffalla AA (1982) Simultaneous use of a sensitive filtration technique and reagent strips in urinary schistosomiasis. Trans R Soc Trop Med Hyg 76: 416-421.

21. Naus CW, van Dam GJ, Kremsner PG, Krijger FW, Deelder AM (1998) Human IgE, IgG subclass, and IgM responses to worm and egg antigens in schistosomiasis haematobium: a 12-month study of reinfection in Cameroonian children. Clin Infect Dis 26: 1142-1147.

22. Abdel-Azim A, Rafick MM, el-Tahawy M, Fikry AA (1989) Total and specific immunoglobulin E in schistosomiasis. J Egypt Soc Parasitol 19: 497-506.

23. Gunderson SG, Haagenson I, Jonassen TO, Figenschau KJ, de Jonge N, et al. (1992) Quantitative detection of schistosomal circulating anodic antigen by magnetic bead capture enzyme- linked immunosorbent assay (MBAC- ELISA) before and after mass chemotherapy.Trans R Soc Trop Med Hyg 86: 175-178.

24. Nash TE, Deelder AM (1985) Comparsion of four schistosome excretory - secretory antigens: phenol sulphuric acid active peak, cathodic circulating antigen, gut, associated proteoglycan and circulating anodic antigen. Am J Trop Med Hyg 34: 236- 241.

25. Onori E, Mccullough FS, Rosei L (1963) Schistosomiasis in the Volta region of Ghana. Ann Trop Med Parasitol 57: 59-70.

26. Polman K (2000) Epidemiological application of circulating antigen detection in schistosomiasis. University of Leiden.

27. Steinmann P, Keiser J, Bos R, Tanner M, Utzinger J (2006) Schistosomiasis and water resources development: systematic review, meta-analysis, and estimates of people at risk. Lancet Infect Dis 6: 411-425.

28. van Dam GJ, Wichers JH, Ferreira TM, Ghati D, van Amerongen A, et al. (2004) Diagnosis of schistosomiasis by reagent strip test for detection of circulating cathodic antigen. J Clin Microbiol 42: 5458-5461.

29. Mduluza T, Ndhlovu PD, Madziwa TM, Midzi N, Zinyama R, et al. (2001) The impact of repeated treatment with praziquantel of schistosomiasis in children under six years of age living in an endemic area for Schistosoma haematobium infection. Mem Inst Oswaldo Cruz 96 Suppl: 157-164. 